\title{
Postpartum Women's Lived Experiences of Perinatal Intimate Partner Violence in Wolaita Zone, Southern Ethiopia: A Phenomenological Study Approach
}

\author{
Tafesse Lamaro Abota (iD) ${ }^{1,2}$ \\ Fikre Enqueselassie Gashe ${ }^{2, \dagger}$ \\ Negussie Deyessa Kabeta ${ }^{2}$ \\ 'Department of Nursing, College of \\ Health Sciences, Mizan-Tepi University, \\ Mizan-Aman, South West Ethiopia; \\ ${ }^{2}$ School of Public Health, College of \\ Health Sciences, Addis Ababa University, \\ Addis Ababa, Ethiopia
}

†Professor Fikre Enqueselassie Gashe passed away on October 28, 2019.
Correspondence: Tafesse Lamaro Abota Email lamaro.tafesse@yahoo.com
Objective: Perinatal intimate partner violence affects the health and safety of postpartum women and their infants. However, it has not been well recognized and addressed in the study setting. Hence, this study aimed to explore postpartum women's lived experiences of perinatal intimate partner violence and its contributing factors in Wolaita Zone, Southern Ethiopia.

Methods: A phenomenological study approach was used to explore postpartum women's lived experiences of perinatal partner violence from January to March 2020. A total of twenty-two postnatal women and five health extension workers (HEWs) were interviewed. Interviews were audio-recorded, transcribed verbatim in local languages, and then translated into English. Data were analyzed thematically, using deductive and inductive coding. The consolidated criteria for reporting qualitative research (CORE-Q) checklist was followed to report the findings.

Results: Results indicated that postpartum women had experienced recurrent violence before, during, and after pregnancy from their husbands, with 16 out of 22 women being subjected to perinatal intimate partner violence. A majority of the participants delineated their exposure to perinatal physical violence next to perinatal psychological violence. Many of the interviewed women noted that violence during pregnancy was exacerbated and increased during postpartum. Moreover, the interviewees revealed that some partners were not only a serious threat to their wives, but also their infants during the postpartum period. Four of the participants stated that their newborns were hit and thrown by their father and became unconscious. Participants linked husbands' perinatal violence with suspicion about the newborn, male-child preference, partner infidelity and jealousy, contraceptives usage, alcohol consumptions, indifference to shortages on household necessities, improper parenting, and financial problems.

Conclusion: This study highlights that postpartum women are experiencing continuous and severe forms of perinatal IPV in the study setting. Thus, community-level interventions that minimize perinatal partner violence against postnatal women and their infants are needed.

Keywords: postpartum women, perinatal, violence, phenomenological, Ethiopia

\section{Introduction}

Intimate partner violence (IPV) is an invasive social and public health problem, which compromises women's physical, mental, sexual, and reproductive health regardless of age, education, economic status, race, religion, ethnicity, or sexual orientation. $^{1,2}$ It is a broad concept and occurs in many forms, including physical violence, sexual violence, stalking, and psychological violence between two people in intimate relationship. ${ }^{3}$ Physical violence can include a deliberate use of physical 
force, like; scratching, slapping, hitting, kicking, beating, shoving, throwing, grabbing, choking, shaking, hairpulling, burning, and use of weapons, which can cause mild to severe injuries. Psychological violence comprises, but is not limited to; insulting, belittling, and constant humiliation, intimidation, verbal threats, and threats to take away children. Sexual violence incorporates rape, forced sexual intercourse, and other forms of sexual coercion. ${ }^{3,4}$ From global estimates, one in three women experiences violence in their lifetime from someone they know; mainly from intimate partners. ${ }^{5}$ Rates of IPV are unacceptably high in the Sub-Saharan region, particularly in Ethiopia. ${ }^{2,6,7}$ Nearly half of Ethiopian women experience at least one form of IPV in their lifetime. ${ }^{8}$ According to the World Health Organization (WHO) report, Ethiopia ranks first in reporting physical and/or sexual violence against women. ${ }^{5}$ In addition, one in three women do not disclose partner abuse in Ethiopia. ${ }^{9}$

Ballard et al identified four patterns of perinatal partner violence that measure persistence, including: violence begins (starts at pregnancy), violence continues (before and during pregnancy), violence ceases (before but not during pregnancy), and no violence (no violence at any stage). ${ }^{10}$ Presumably, IPV has no limits, occurring during reproductive life, but women are more likely to experience violence during pregnancy and postpartum. ${ }^{11,12}$ In addition, immense physical and psychosocial changes taking place during the perinatal period poses a great risk of IPV. ${ }^{13}$ Due to intensified motherhood role, women are particularly susceptible to poor health immediately following childbirth. ${ }^{14}$ The growing evidence demonstrates an increment of existing violence as postpartum develops. ${ }^{15-17}$ It is noted that perinatal IPV is an important indicator of severe violence. ${ }^{18}$ However, issues regarding perinatal IPV against postpartum women and developing infants has not been adequately researched. ${ }^{13}$

Perinatal IPV has negative impacts on the health and safety of postpartum women and their infants. It is associated with postpartum depression, ${ }^{19,20}$ psychological stress, less work satisfaction, inadequate hospitalization of babies, poor breastfeeding behavior, infant mortality, and child malnutrition. ${ }^{21-23}$ It is also linked with some postpartum health risks, such as partner imposed fear of condom negotiation and usage, infants sleeping problems, and parental stress. ${ }^{24}$ Moreover, there are several risk factors for perinatal IPV like; younger women, ${ }^{16,25}$ low education status, low socioeconomic status, ${ }^{26,27}$ depression, poor social support ${ }^{21,28}$ and lack of agreement on contraceptive use, ${ }^{29}$ which may increase the risk of perinatal partner violence. To date, several IPV studies have been conducted in Ethiopia, but only a few explored perinatal IPV for the postpartum population. To understand and provide appropriate assistance and support for postpartum women living in an abusive relationship, it is important to have deep knowledge about their experience. Therefore, this study explores postpartum women's lived experiences of perinatal IPV, particularly the major forms of IPV (psychological, physical, and sexual violence) and its contributing factors using a phenomenological study approach.

\section{Materials and Methods Study Setting and Period}

The study was conducted in Wolaita Zone. Wolaita Zone is located in the Southern Nations, Nationalities, and People's Region. Wolaita Sodo is its capital town which is $330 \mathrm{~km}$ south of Addis Ababa, Ethiopia. The zone is administratively divided into sixteen districts (woredas) and six town administrations. It is one of the most densely populated zones with an estimated total population of 2.5 million people. It has a total of 310,454 households with an average household size of 4.84 persons and 297,981 housing units. ${ }^{30}$ There are 7 hospitals (5 governmental and 2 private), 68 health centers, and 345 health posts located within zone. ${ }^{31}$ On average, two Health Extension Workers (HEWs) are assigned to each health post. The study was conducted in the five rural health posts (Sura Koyoo, Kindo koyoo, Dolla, Bossa Kacha, and Bilbo Bedessa) and one Women, Children and Youth Affairs (WCYA) department (Sodo city) between January to March 2020. In the context of our study, the population of interest was postnatal women who reported any violence grievances, either to health posts in the rural setting or WCYA in the urban setting. These study sites were conveniently selected based on the potential to access victims exposed to partner violence.

\section{Study Design}

The phenomenological study approach was employed to explore perinatal IPV experiences lived by postpartum women living in the Wolaita zone. The phenomenological approach underpins the interpretive ontological and epistemological paradigm, which seeks to understand the lived experience through the eyes of the people experiencing it. ${ }^{32}$ In this study; the above approach offers an opportunity to 
explore the postpartum women's lived experience of perinatal IPV. This approach allows the researcher to understand not only the individual's lived experience but also the condition surrounding it. ${ }^{32,33}$ In this process, phenomenology values both philosophy and method. Moreover, this approach also provides many opportunities for interviewees, including catharsis, self-reflection; healing, empowerment, and sense of purpose. ${ }^{33}$

\section{Participant Recruitments}

A total of twenty-two participants were recruited from urban and rural settings with the help of HEWs and the head of WCYA. The inclusion criteria included; currently married postpartum women aged 18 years and older with index children aged below twelve months and reporting violent grievances either to health posts or the WCYA Department. Participants were recruited using the convenience sampling method and consecutively interviewed at each site ${ }^{34,35}$ where informal interviews were conducted before sequential questioning. ${ }^{36}$ No postpartum women who fulfilled the inclusion criteria and were approached for an interview declined to participate in the study. Similarly, five HEWs from different rural health posts who interact with women seeking treatment for other conditions $^{37}$ were also interviewed. Health extension workers who had a minimum of a college diploma in health science, and have been working in the health extension program at health posts for more than two years were included in the interview. The data saturation ${ }^{38}$ was achieved with the $22^{\text {nd }}$ interviewee and further data collection stopped.

\section{Interviews}

Semi-structured, in-depth interview guides were used to gather data from two groups of respondents: postpartum women violence victims and HEWs. Different interview guides were used to interview the two respective groups (Supplementary File 1). The interview guides for postnatal women consisted of main and probing questions such as; socio-demographic characteristics, marriage history, index pregnancy intention, contraception, and perinatal IPV experiences for index birth. For instance, some of the main questions asked to interviewees were:

Could you please tell me a little about yourself and your husband? How did you come to know him? What is your main reason to visit this institution? When did your problems with your husband start? How does he treat you in front of others in the perinatal period? Could you tell me if your partner has ever inflicted any physical harm on your body in the perinatal period? Could you tell me if your partner harassed you sexually in the perinatal period? How can you explain your husband's feelings about contraceptive use before pregnancy versus now?

The interview questions for HEWs probed reasons for postpartum women visiting the health post, reporting of IPV, and types of IPV reported.

Interviews were conducted face-to-face with participants in a private and quiet environment, which was either at the health posts or WCYA department based on their personal preferences. Participants were interviewed in both Amharic and Wolaita languages. A neutral single bilingual interviewer [TL], a male principal investigator, who had a Master in Reproductive and Maternal Health and was experienced in qualitative research, conducted the interviews to avoid interinterviewer differences. The interviewer had no contact with the service centers to ensure there was no effect on their responses. An empathetic rapport was made with each interviewee for five to seven minutes. At the beginning of the interview, permission was requested from each interviewee to record the audio. Each participant was interviewed separately. The length of the interviews was thirty-five minutes on average. Field notes were recorded to include key messages and participants' nonverbal cues. After interviewing the first four participants, the interview guide was slightly modified to accommodate new ideas. Two pilot interviews were conducted with HEWs to validate interview guides. However; no changes were required. All study participants were compensated with one hundred Ethiopia birr (about \$3) at the end of interviews.

\section{Data Management and Analysis}

The transferability of the findings was ensured by collecting data from two target groups for triangulation. ${ }^{33}$ All audio recordings were transcribed verbatim and translated to the English language. Audit trails for the transcribed data were done with each interviewee to ensure trustworthiness and to minimize errors. All transcripts of the interviews were checked for errors by the simultaneous readings of the transcripts beside the audio-recorded voices. Final transcripts were also compared with field notes to ensure quality. Verbatim transcripts were analyzed using the OpenCode software version 4.02 for computer-assisted coding and 
categorization. The text was read several times to be familiar with the data. Line-by-line coding was then conducted by the principal investigator [TL]. The key attributes of each term or narrates were coded and tallied and later used to create categories. The codes were compared based on their similarities and differences and then subsequently grouped into categories. Data were analyzed thematically, using deductive and inductive coding ${ }^{38}$ where salient quotes were used to support the themes. The consolidated criteria for reporting qualitative research (COREQ) from a 32- item checklist was used to report the findings. ${ }^{39}$

\section{Results}

\section{Background Characteristics of Study Participants}

A total of twenty-two in-depth interviews with postnatal women were conducted. All respondents were married. Almost half of them were living with their husbands at the time of the interview. About two-thirds of the participants were between 19 to 25 years. The minimum and maximum ages of the interviewees were 18 and 41 years, respectively. The average age at first marriage was 18.8 years. More than half (12 of 22), of the participants were from a rural setting. Except few (3 of 22), all participants were housewives and daily laborers by their occupation. A majority had attended formal education. However, only one of them had a college diploma. Two-thirds of the participants had between two to eleven children with the age of the index child ranging from three to twelve months. With respect to family planning, only 6 participants were using postpartum contraceptives at the time of the interview. Duration of stay in abusive relationships ranged from two to twenty-two years. Five key informant interviews with HEWs were also conducted in the selected rural health posts. All of the key informants were females. Their ages ranged from 29 to 42 years, and all were married. Three had completed college diploma, and the other two had university-level education. Four of them had at least five years of work experience, and one had three years of experience. In-depth and key informant interviews findings were combined. Three main themes emerged from data: “women's experience of major forms of perinatal IPV (psychological, physical and sexual violence)", "factors associated with perinatal IPV /m', and " implications of perinatal IPV on women's health” (Supplementary File 2).

\section{Postpartum Women's Lived Experiences of Perinatal IPV}

Study participants explicitly shared their hard hit by perinatal IPV. According to the reports, several of the interviewed women suffered from various perinatal psychological, physical, sexual, and economic violence, controlling behaviors, and deprivation of basic needs: food, money, clothing and housing. Their experience of perinatal IPV ranged from mild to severe, in which many (16 of 22) reported recurrent violence occurrence before, during, and after pregnancy. Some of the participants in the interview narrated that violence started at the beginning of their relationship. A majority of the interviewees indicated that violence during pregnancy was exacerbated and increased in the postpartum (Supplementary File 3). Some of the respondents had this to say:

He forced me [to have sex] within fourteen days of having a child. (P-1)

He keeps saying this, 'We will meet after your safe birth'. (P-2)

He just kicked me, but I did not react to him since I was in postpartum. However, he often injured me when I was pregnant. (P-8)

She came here with a three-day old infant ... her husband had beaten her very badly. We all cried about her. (HEW-2)

\section{Perinatal Psychological IPV}

The interviewed women explicitly delineated their vulnerability to psychological violence before, during, and after the birth of an index child. Sixteen of the participants had experienced recurrent psychological violence within three distinctive periods. The majority of interviewees narrated that they were verbally abused, including; insulting, humiliation, intimidation, name-calling, belittling, and more. However, the interviewed women had trouble elaborating on how they had been subjected to severe perinatal psychological IPV. In addition, some of the study participants were embarrassed to explain the name-calling they encountered. For example, one of the participants explained that:

He called me 'a bar lady'. How can I tell you all his insolent? He insults me in all manners. 'I saw you here and there ...' I am very afraid to mention what he said. (P-5) 
The subsequent threats to hit, beat and kill were prominent in women's responses. In most cases, husbands used body language, otiose words, and beatings to intimidate their wives.

... but he scares me. 'I will show you my hidden identity that you have never known. I will discipline you; hmm ... I will give your result'. He raised his hand to hit [showing his action of intent to hit]. (P-3)

Additionally, violence victims were also abused psychologically by their in-laws and friends. As five of the interviewed women explained, the perinatal verbal assault occurred in the forms of intimidation, mocking, and teasing. Some of the participants had this to say:

... that woman sent me gangsters to hit me ... not meet with him [husband] again. (P-2)

... I said, 'they made crops to be eaten. Your brothers made me suffer. I was insulted; they harassed me because I told them [brothers-in-law] to keep their cows enclosed'. (P-6)

\section{Perinatal Physical IPV}

As revealed from the data, sizeable proportions of postpartum women are at higher risks of experiencing perinatal physical IPV. Ten participants experienced subsequent physical partner violence from their husbands before, during, and after pregnancy. About 12 participants experienced physical violence during pregnancy while sixteen had it during the postpartum period. A majority of the participants noted that physical violence was exacerbated and increased during and after childbirth, including; slapping, kicking, hitting, beating, strangling, repeated pushing, and punching. Some of the interviewees stated that their husbands had repeatedly beaten them or kicked at vulnerable parts of their body including the abdomen during pregnancy. One participant, for example, said the following:

... He approached from the back and kicked me when cooking dinner. Immediately, I fell towards the fire and got injured. After I fell to the ground, we went to a traditional birth attendant's house and she told us I was pregnant. (P-2)

Another interviewee reported:

... He kicked my abdomen and went out. At the time, I was three months pregnant. (P-15)

According to participants' narrations, severe physical attacks were common in the perinatal period, like threats with knives, big sticks, and throwing objects (coffee cups and pots, tea-cups and chairs). Consequently, participants lost their tooth or hearing or had broken hands and legs. As four of the interviewed women explained their husbands continuously attacked them with knives.

Since our wedding, he has hit me with whatever he found ... even by 'Kincora' [big knife] until people called him crazy. I reported him once and had him jailed here in the Keble [lowest administrative unit in Ethiopia] because of using a Kincora. (P-4)

... then he beat and broke my hand. (P-5)

... In this community, many women have been stabbed by their husbands and they never help to get medical treatment after stabbing ... this week, a woman came for treatment after being stabbed by her husband, three weeks after child-birth for trivial reasons. (HEW-4)

In this study, interviewees briefly described the spillover effect of perinatal violence. The data from the interviewees revealed that some partners were not only a serious threat to their wives, but also the infants during the postpartum period. Four of the participants mentioned that their newborns were hit and thrown by their father from a high distance and became unconscious, as a result of physical quarreling between partners. One interviewee stated the following:

... He started a conflict with me and grasped the baby and threw her from a high distance ... the baby was unconscious for a long time. (P-1)

\section{Perinatal Sexual IPV}

The interviewees experienced various forms of sexual abuse, ranging from sexual misconduct to unwanted sexual encounters without their consent in three mutually exclusive periods. Ten participants reported sexual violence before pregnancy while eight reported violence during pregnancy, but some participants were severely sexually assaulted at the verge of pregnancy. An interviewee shared her experience in the following way:

... I cried and shed tears until people gathered. Family shouted at him,' ... shame on you! Why did you do that to her. She is powerless'. Then, I gave birth at night towards morning hours. (P-5)

Another participant said: 
... If I refuse it [sex], he beats me. He pushed me to lie down on the bed when I was pregnant. It [forceful sex] is exacerbated after childbirth. (P-19)

The majority of interviewees experienced postpartum sexual violence. In the first few weeks of postpartum, some participants were exposed to forceful, nonconsensual sex. The women performed unwanted sex because they feared their husbands' frequent battering. Some respondents said the following:

One night he asked and forced me to have sexual intercourse without my willingness. Due to lack of power; I submitted my body to his sexual demands. (P-1)

... I submitted to his sexual demands because I was frightened that he would beat me. What can I do? You can't equate women's and men's power. (P-4)

... One woman said that,' I never want him. I can't tolerate it [forceful sexual intercourse].' She asked for divorce following this issue. (HEW-2)

... Many husbands use excessive forces including kicks and slaps to sleep [to have sex] with their wives. (HEW-4)

According to most of the participants, sexual libido decreased after childbirth. Many claimed that maternal responsibilities, including; breastfeeding, childcare, physical inactivity, and poor nutrition were associated with reduced sexual impulses. About seven of the interviewed women reported a lack of sexual libido. For example, two participants said this regarding sexual desire:

... To do it [sex], first my body felt burdened, second I'm breastfeeding and third, he doesn't worry about my hunger and thirst. Due to those reasons; I don't want it [sex]. (P-2)

... Previously, when our body was full; when we drunk and ate ... it [sex] was very pleasing to do it ... We did it as we wanted. Right now, I do not know, hate it. (P-6)

\section{Factors Associated with Perinatal IPV}

Regarding factors associated with perinatal IPV, participants mentioned several issues that could be assumed to be causes of such incidences, including; alcohol consumptions, suspicion about the newborn, preference for a male child, partner infidelity and jealousy, use of contraceptives, indifference to shortages on household necessities, lack of proper parenting and financial problems.

\section{Excess Alcohol Consumption}

As revealed from the data, excess alcohol consumption often contributed to violent events. Many participants reported that alcohol abuse led to severe marital tension. About one-third of the participants experienced mixed or overlapping forms of perinatal IPV because their husbands were intoxicated. The story of two participants is revealed in the following narratives:

... At times; I was powerless [at the verge of pregnancy]. 'Where are you going? I will be asked by neighbors,' he said and he punched me because he was drunk. (P-10)

... When drunk, he insults me very badly ... 'You! The son of bitch! Eat your mom's 'Entinaa' [Vagina]. (P-17)

The study participants also narrated that the risk of perinatal violence increased when their husbands abused alcohol. Four women's narratives show that their husbands displayed out-of- control behaviors when intoxicated.

... Because of that, baby lost her breath for a long time. When he did this, he was not aware of it because he was drunk. (P-1)

After drinking spree, he beats me when he comes home as drunk ... in worthy and in vain, he insults me. Drinking is part of his life. (P-11)

\section{Suspicion About Newborns}

As revealed from the data, husbands are suspicious about babies born less than nine months. It is known that women may give births in a short gestational period (premature births) due to different causes. However, the interviewed postpartum women narrated that the suspicion about newborns were the reason for their abuse. According to the reports, three women's husbands had doubts about their newborns. According to the following narratives, two interviewees elaborated on the suspicion of newborns.

... Immediately after giving birth, I called and informed him about the birth. He said, 'No! It is seven months, not nine months. (P-7)

... During the negotiation with some husbands; they say, 'I don't accept the last child like mine. She had gone to her family in the last fight. (HEW-3)

\section{Preference for a Male Child}

The reports from the interviewees indicated that partners' preferences for male children triggered perinatal IPV. Four of the interviewees experienced postpartum violence due 
to giving birth to female infants. As a result, they were insulted, belittled, kicked, and beaten by their husbands. In some instances, after finding out that the child was female, the husbands injured and tried to kill the newborn. The interviewed women also reported that their abusive husbands wanted to know the sex of the unborn child during antenatal follow-up.

... He came after two days and saw it's a baby girl. Afterwards, he quarreled with me, grabbed the baby from my hands and threw from a high distance. From his evil ideas, he threw the baby. (P-1)

... I had consecutive births of baby girls. Due to this case, we quarreled before. With the help of God, I delivered a baby boy by this year and he is good to me now. (P-13)

... After getting an antenatal checkup for the last pregnancy, he wanted to know the sex of the coming child. (P-7)

\section{Partner Jealousy and Suspicion of Infidelity}

Jealousy is another provoking factor that was revealed during the interviews with participants. It is considered a warning sign of abusive relationships. As delineated from the interview participants, their abusive partners have a pervasive sense of jealousy. Two of the interviewees said the following:

... He stays away from the house by pretense and suddenly came home to see if I was home or not. (P-9)

... He didn't let me go to the market and didn't allow me to go out. I wouldn't speak if one of my family members came to our house. We just couldn't speak ... he was waiting. (P-5)

Similarly, partner infidelity was also reported to lead to IPV between partners. The interviewees reported that partner infidelity was the source of quarrels with their partners.

... He had a close friendship with a neighboring woman. She is a good person. However; he made her his intimate friend. (P-8)

... we quarreled after I heard that he was in a relationship with someone. Then, I went to my family and later he called me and said, 'don't come upon my life. I started my own life. You can continue your own life.' (P-12)

... Commonly what we hear here; men are not tolerant. They desire other girls. (HEW-3)

\section{Use of Birth Controls}

Reproductive rights are fundamental to women's autonomy. However; according to some interviewees; initiation, stopping, and switching of contraceptives is controlled by their husbands. Nearly one-third of the interviewed women delineated that initiating contraceptives triggered perinatal physical and/or psychological IPV experiences. Consequently, interviewees repeatedly stated that they had been coerced, abused, and forced by their husbands to stop birth control.

... When I came from my family home I have brought the birth control pills, but he forbids me to use. For instance, one day he found the pills from where I put and secretly hid them. (P-1)

... He beats me ... 'Remove what you inserted [implanon] in your hand? You are living simply. You are not worthy without giving me more children,' he said. (P-2)

The majority of interviewees demonstrate that they had repeated conflict and fought because of using birth control methods. Further interviewees reported that some husbands were too aggressive for them to use birth control. Three women suffered severe physical violence due to the use of contraceptives.

... I didn't get pregnant as I was on contraceptive use for two years. 'You stayed two years due to an injection,' he said. Then he beat and broke my hand. (P-5)

... However, he insisted to stop using the injection [implanon] and I said no. We engaged in conflict and fought. Then, in front of people he gathered, I said that he was not good for me even the first Child. Due to this case, we quarreled in front of the gathered people. (P-2)

... Once he dangerously beat me due to it [birth control] and I got sick for four weeks (P-18)

\section{Family, Neighbors, and Peer Involvement}

Interference from third parties may be "cancerous" and shake the bases of many marriages. According to study participants, the involvement of family and peers were the main source of their quarrels. Eight of the twenty-two interviewees reported that families, neighbors, and/or peers' ill involvement were an associated factor for perinatal IPV. Some of the participants had this to say regarding family, neighbors and peers' ill involvement: 
He screamed at me. For that matter; the problem was raised by the family. We started fighting because of family issues. (P-2)

... There are many families, friends, and neighbors that disturb marriage bases. (HEW-2)

Additionally, reports from the participants indicated that some abusive husbands beat, kicked, and threatened their wives with knives because of their neighbor's involvement with their affairs. Two of the respondents experienced violence by their husbands when a dispute occurred with their neighbors:

Once upon a time when I was four months pregnant, I was cleaning our home and a woman next to our door abused me. As soon as my husband arrived to the home he has slapped me by supporting her. After that, one ear stopped hearing. (P-1)

Women from the neighborhood told him that I had visited women's affairs office ... she told him that he should discipline me. After that, he constantly threatened me with a knife. He just became skeptical since he believes that I took someone else's advice. (P-9)

\section{Implications of Perinatal IPV on Women's Health}

The stories the study participants narrated show the various effect of perinatal IPV, including unintended pregnancies, repeated miscarriages, elevated blood pressures, and physical injuries. Almost half (12 of 22) of interviewees experienced unintended pregnancies. As five of the interviewed women stated, losing their tooth or hearing or had broken hands and legs occurred as a result of their partner's physical violence. In addition, some of the victims reported that they remained physically dependent. Six out of the twenty-two interviewees reported a history of miscarriages. Of these, two women encountered repeated miscarriages. One respondent reported increased blood pressure. Some of the victims shared their experiences and said the following:

... My blood pressure rose unknowingly as we had quarrels each other and shouted for this and that. (P-3)

... at night time, I lost to sleep. I thought I would be killed at night. (P-9)

... I suffered a lot due to miscarriages, unknowingly. It affected me a lot. I miscarried twice here. It damaged me severely since I had lost a lot of blood. (P-6)
The study participants also reported that repeated and severe violence resulted in mental health problems, like; sleeping disorders, mental trauma, and suicidal thoughts and attempts. Three respondents explained that they developed sleeping disorders. Six of the participants delineated mental trauma. Of these six, two had several suicidal attempts. Following experiences of violence, three interviewees tried to throw and kill their newborns. Some of the participants had the following statement:

$\mathrm{hmm} . .$. he was angry and looked weird ... with red eyes. I couldn't sleep at night and I thought he could do something to me. (P-3)

... I thought many times about committing suicide.

I attempted to kill my daughter many times. (P-7)

... Like a crazy person, I cried in my house and tried to throw the baby into the pit. (P-20)

\section{Discussion}

The violence of any kind is unacceptable Postpartum women and their infants deserve safety and protection from sexual, physical, psychological, or verbal violence. In the current study, participants who experienced partner violence either before or during pregnancy continuously reported postpartum violence. This concurs with other findings; women with a history of violence are at risk of future violence. ${ }^{40-43}$ Consistent with a study conducted in Australia, ${ }^{40}$ perinatal IPV increases over time. The possible reason might be, for some couples, the transition to parenthood can be a stressful time and demanding additional physical, psychological, social, and economic needs. If it is difficult to cope up with such relationship stress; it could result in continued abuse. Results show that participants had psychological violence in three mutually exclusive periods accompanied by physical violence. Studies suggest that psychological violence predominantly occurs in physically violent relationships and is a precursor for other forms of partner violence. ${ }^{3,44,45}$ Psychological violence is the most prevalent and severe form of violence. $^{46,47}$ Indeed, it is the most under-researched form of violence. This indicates that a single abusive incident could result in many forms of perinatal violence. In the present study, a substantial portion of interviewees experienced perinatal sexual IPV which occurred at its earliest within the first two weeks of postpartum. Two postpartum women experienced forcible rape from their husbands, which resulted in reproductive tract bleeding 
and infections. Similar to other studies, ${ }^{48,49}$ forceful nonconsensual sex against women is common in consensual unions. This is a great implication for the fact beyond perinatal IPV and it could result in severe comorbidity.

Results from this study suggest a link between husbands who abuse alcohol and perinatal violence. Likely, the finding reveals that alcoholism leads to many household problems, including; psychological, physical, and sexual violence. ${ }^{50}$ Compared to women experiencing no violence, women experiencing violence reported that partners chronically abused alcohol. ${ }^{51}$ However, alcohol misuse is a double burden and difficult to shoulder in this formative period. In the present study, suspicion about the newborn also increases the risk of violence. Similar to reports from the United States, the frequency and severity of perinatal IPV increased with doubts about the paternal resemblance. ${ }^{52,53}$ The reason might be that abusive partners are more likely to be suspicious of their wives being unfaithful, which could lead to more conflict. It is worth mentioning that one participant in this study experienced violence due to pre-term birth. Literature indicates that women in violent relationships are at increased risk of experiencing pre-term births, but such births do not necessarily trigger violent incidents. ${ }^{54-56}$ The possible justification could be a wrong perception about pre-term births ie births less than thirty-seven weeks of gestation are assumed as cheating. Corroborating to studies set in Ethiopia, Nigeria, and the United States, ${ }^{50,57,58}$ partner infidelity and jealousy precipitated husbands' violence in postpartum. A husband's preferences for a male child increased incidents of perinatal IPV. Correspondingly, a study conducted in Pakistan found that the inability to give birth to male children is linked to perinatal violence. ${ }^{49}$ In a patriarchal and hypermasculine society, husbands highly desire sons over daughters. ${ }^{59}$ The possible reason might be discriminating gender norms: sons can honor their family at a social level, unlike daughters. Additionally, the subsequent birth of baby girls is considered the woman's fault in a patriarchal society. Societal or cultural beliefs may require creative ways to improve community awareness regarding issues of gender and reproductive health rights. The use of contraceptives without the husband's consent was also a risk factor for perinatal violence. Presumably, ongoing perinatal IPV was associated with reduced contraceptive use. ${ }^{24}$ Reproductive coercion; including contraceptive sabotage was also commonly reported by women experiencing partner violence. ${ }^{29,60}$
Perinatal IPV tampers with several women's mental and reproductive health. In this study, respondents reported that previous unwanted pregnancies, miscarriages, high blood pressure, and reproductive tract infections and bleeding occurred due to perinatal IPV from their husbands. These findings are consistent with other studies. $^{24,29}$ Additionally, women in this study narrated that they had developed perceived stress, fears, sleeping disorders, and other mental illnesses, indicating similarities with other several studies conducted elsewhere. ${ }^{19,24,61}$ Some participants exhibited suicidal thoughts or attempts due to postpartum anguishes. Similarly, a report from Brazil indicated that suicidal ideation was common in twothirds of low-income postpartum women reporting partner violence. ${ }^{62}$ The effect of continuous partner violence leads to child abuse and neglect, ${ }^{63,64}$ as also evidenced by this study.

\section{Strengths and Limitations of the Study}

This qualitative evidence provides some insights into the nature of perinatal IPV in the study setting. However, there are significant limitations while using this research finding. Participants were recruited using convenience sampling method, which fails to reach hard-to-reach victims. Some of the participants were traced with the help of health extension workers. This may have introduced selection bias. Moreover, only a male principal investigator [TL] collected data. Due to the sensitive nature of the topic in relation to gender roles, this may have prevented women from disclosing the full extent of their experience of IPV. Despite these limitations, this study has some important implications. To the best of our knowledge, this is the first study to explore postpartum women's lived experience of perinatal IPV in Ethiopia in general and in the study area in particular. Attempts were made to interview different groups of participants to triangulate findings. To ensure the integrity of the collected data, the verbal transcripts were read to each interviewee and feedback was incorporated. Our study included both urban and rural residents, which could represent both communities. In addition, women living with their abusive husbands and women who left violent relationships were also involved in this study. Thus, this study could show the actual nature of the problem in the health and social service settings. However, the future study requires to understand the extent of the problem in the community. 


\section{Conclusion}

This study highlights that postpartum women are experiencing continuous and severe forms of perinatal IPV in the study setting. The circumstances leading to perinatal IPV are multifactorial. However, intimate partner violence and perinatal period complexities and burdens are indicated as an interplaying challenge. Thus, community-level interventions that minimize perinatal IPV among postpartum women and their infants are needed. Improving gender equality and women empowerment by harmonizing efforts with the individual, community and local authorities could also alleviate contributing factors. Moreover, routine screening programs should be launched in the perinatal period since it offers a great opportunity to recognize and intervene in the initial or continuous violence against women and their infants.

\section{Data Sharing Statement}

The data, both audio records and transcripts, analysed during the current study are available from the corresponding author upon reasonable request.

\section{Ethical Approval and Informed Consent}

The ethical clearance was obtained from the Institutional Review Board (IRB) of Addis Ababa University College of Health Sciences with a protocol number of 006/19/SPH. The study followed basic ethical principles of Helsinki declaration for medical research involving in human subjects. ${ }^{65}$ All of the study participants were briefed about aims and procedure of the research and their right to abstain or withdrawal from the study at any time. Written informed consent was obtained from each participant separately. Participants were well informed not to mention a third person's name during audio recordings including their own respective names. The confidentiality of the collected data was maintained by assigning unique anonymous coding (P-1, P-2, P-3 ...). All study information was kept secured and confidential with the first author. All audio recordings and transcribed data was not disclosed to third parties without the consent of the participant. All study participants provided informed consent to have their quotes published. After the interview, participants were given the opportunity to visit a psychiatric nurse if they experienced any psychological discomfort.

\section{Acknowledgment}

All authors express their gratitude to the Addis Ababa University College of Health Sciences for providing financial support and ethical approval for this research. We are very grateful to one of our staff, mentors and supervisors, Fikre Enqueselassie, whom we missed suddenly during this manuscript preparation; May his soul rest in perfect peace. We would like to thank the staff of the WCYA department of Wolaita Soddo city for their cooperation and facilitation in arranging eligible study participants. We are indebted to HEWs for genuine support in tracing eligible participants. We are also grateful to all the study participants for sharing their personal information.

\section{Author Contributions}

All authors contributed from the conception of topic to data analysis, drafting or revising the article, have agreed on the journal to which the article will be submitted, gave final approval of the version to be published, and agree to be accountable for all aspects of the work. Specifically, TL was conceptualized the topic of interest, involved in data collection, transcribed and translated data, conducted data analysis and drafted the manuscript. FE was involved in proposal development, planning the fieldwork and result section. ND: was involved in proposal and interview guides' development, data analysis and write up and in critical reviewing of manuscript.

\section{Funding}

Addis Ababa University, College of Health Sciences provided financial support for the data collection. It is a public university in Ethiopia and grants small amounts of money to $\mathrm{PhD}$ candidates for data collection. Therefore, the university has no conflicts of interests in this study. No other funding was obtained for the current study.

\section{Disclosure}

The authors declare that they have no competing interests.

\section{References}

1. Word Health Organization. Preventing Intimate Partner and Sexual Violence Against Women: Taking Action and Generating Evidence; 2010.

2. García-Moreno C, Pallitto C, Devries K, Stöckl H, Watts C, Abrahams N. Global and Regional Estimates of Violence Against Women: Prevalence and Health Effects of Intimate Partner Violence and Non-Partner Sexual Violence. World Health Organization; 2013.

3. Breiding MJ, Basile KC, Smith SG, Black MC, Mahendra RR. Intimate Partner Violence Surveillance: Uniform Definitions and Recommended Data Elements, Version 2.0.Atlanta(GA):National Center for Injury Prevention and Control,Centers for Disease Control and Prevention; 2015. 
4. World Health Organization. Understanding and Addressing Violence Against Women: Intimate Partner Violence. World Health Organization; 2012.

5. World Health Organization. WHO Multi-Country Study on Women's Health and Domestic Violence Against Women: Initial Results on Prevalence, Health Outcomes and Women's Responses. World Health Organization; 2005.

6. Kaneda T, Smith R. Intimate Partner Violence and Unmet Need for Family Planning: Findings Among Women of Different Ages from Six Sub-Saharan African Countries, PRB Research Brief. Washington, DC: Population Reference Bureau; 2015.

7. World Health Organization.WHO multi-country study on women's health and domestic violence against women: Initial results on prevalence, health outcomes and women's responses. World Health Organization; 2005. Available from: https://www.who.int/reproducti vehealth/publications/violence/24159358X/en/. Accessed November $10,2021$.

8. Kassa GM, Abajobir AA. Prevalence of violence against women in Ethiopia: a meta-analysis. Trauma Violence Abuse. 2018;21:1524838018782205.

9. Bifftu BB, Dachew BA, Tiruneh BT, Gezie LD, Guracho YD. Domestic violence related disclosure among women and girls in Ethiopia: a systematic review and meta-analysis. Reprod Health. 2019;16(1):1-10. doi:10.1186/s12978-019-0845-z

10. Ballard TJ, Saltzman LE, Gazmararian JA, Spitz AM, Lazorick S, Marks JS. Violence during pregnancy: measurement issues. $\mathrm{Am}$ J Public Health. 1998;88(2):274-276. doi:10.2105/AJPH.88.2.274

11. Hedin LW. Postpartum, also a risk period for domestic violence. Eur J Obst Gynecol Reprod Biol. 2000;89(1):41-45. doi:10.1016/S03012115(99)00164-5

12. Campo M. Domestic and Family Violence in Pregnancy and Early Parenthood. Canberra: Australian Government; 2015.

13. Shoffner DH. We don't like to think about it: intimate partner violence during pregnancy and postpartum. J Perinat Neonatal Nurs. 2008;22(1):39-48. doi:10.1097/01.JPN.0000311874.30828.4e

14. Fahey JO, Shenassa E. Understanding and meeting the needs of women in the postpartum period: the perinatal maternal health promotion model. J Midwif Women's Health. 2013;58(6):613-621. doi:10.1111/jmwh.12139

15. Finnbogadóttir H, Dykes A-K. Increasing prevalence and incidence of domestic violence during the pregnancy and one and a half year postpartum, as well as risk factors: -A longitudinal cohort study in Southern Sweden. BMC Pregnancy Childbirth. 2016;16:327. doi:10.1186/s12884-016-1122-6

16. Mohammadhosseini E, Sahraean L, Bahrami T. Domestic abuse before, during and after pregnancy in Jahrom, Islamic Republic of Iran. Eastern Med Health J. 2010;16(7):752-758. doi:10.26719/2010.16.7.752

17. Macy RJ, Martin SL, Kupper LL, Casanueva C, Guo S. Partner violence among women before, during, and after pregnancy: multiple opportunities for intervention. Women's Health Issues. 2007;17 (5):290-299. doi:10.1016/j.whi.2007.03.006

18. Daoud N, Urquia ML, O'Campo P, et al. Prevalence of abuse and violence before, during, and after pregnancy in a national sample of Canadian women. Am J Public Health. 2012;102(10):1893-1901. doi:10.2105/AJPH.2012.300843

19. Tsai AC, Tomlinson M, Comulada WS, Rotheram-Borus MJ. Intimate partner violence and depression symptom severity among South African women during pregnancy and postpartum: population-based prospective cohort study. PLoS Med. 2016;13(1): e1001943. doi:10.1371/journal.pmed.1001943

20. Islam MJ, Broidy L, Baird K, Mazerolle P. Intimate partner violence around the time of pregnancy and postpartum depression: the experience of women of Bangladesh. PLoS One. 2017;12(5):e0176211. doi:10.1371/journal.pone.0176211
21. Romito P, Pomicino L, Lucchetta C, Scrimin F, Molzan Turan J. The relationships between physical violence, verbal abuse and women's psychological distress during the postpartum period. J Psycho Obstet Gynecol. 2009;30(2):115-121. doi:10.1080/01674820802545834

22. Silverman JG, Decker MR, Reed E, Raj A. Intimate partner violence around the time of pregnancy: association with breastfeeding behavior. J Women's Health. 2006;15(8):934-940. doi:10.1089/ jwh.2006.15.934

23. Rico E, Fenn B, Abramsky T, Watts C. Associations between maternal experiences of intimate partner violence and child nutrition and mortality: findings from Demographic and Health Surveys in Egypt, Honduras, Kenya, Malawi and Rwanda. J Epidemiol Community Health. 2011;65(4):360-367. doi:10.1136/jech.2008.081810

24. Agrawal A, Ickovics J, Lewis JB, Magriples U, Kershaw TS. Postpartum intimate partner violence and health risks among young mothers in the United States: a prospective study. Matern Child Health J. 2014;18(8):1985-1992. doi:10.1007/s10995-014-1444-9

25. Silva EP, Ludermir AB, Araújo T, Valongueiro SA. Frequency and pattern of intimate partner violence before, during and after pregnancy. Rev Saude Publica. 2011;45(6):1044-1053. doi:10.1590/ S0034-89102011005000074

26. Silva EP, Valongueiro S, Araújo T, Ludermir AB. Incidence and risk factors for intimate partner violence during the postpartum period. Rev Saude Publica. 2015;7:49.

27. Das $S$, Bapat U, Shah More N, et al. Intimate partner violence against women during and after pregnancy: a cross-sectional study in Mumbai slums. BMC Public Health. 2013;13(1):817.

28. Spangenberg K, Wobil P, Betts CL, Wiesner TF, Gold KJ. Intimate partner violence among mothers of sick newborns in Ghana. Health Care Women Int. 2016;37(5):583-594. doi:10.1080/07399332.2015.1037444

29. Escribà-Agüir V, Romito P, Scrimin F, Turan JM. Are there differences in the impact of partner violence on reproductive health between postpartum women and women who had an elective abortion? Journal of Urban Health. 2012;89(5):861-871. doi:10.1007/s11524-012-9714-6

30. Central Statistics Agency. Population and Housing Census of Ethiopia: Statistical Report for Southern Nations, Nationalities and Peoples' Region; Part I: Population Size and Characteristics; 2007.

31. Cochrane L, Gecho Y. Data on the demographics, education, health and infrastructure: wolaita Zone, Ethiopia. Data Brief. 2018;21:2095-2102. doi:10.1016/j.dib.2018.11.063

32. Nicholls D. Qualitative research: part one - philosophies. Int J Ther Rehabil. 2009;16(10):526-533.

33. De Chesnay M. Nursing Research Using Phenomenology: Qualitative Designs and Methods in Nursing. Springer Publishing Company; 2014.

34. Given LM. The Sage Encyclopedia of Qualitative Research Methods. Sage publications; 2008.

35. Etikan I, Musa SA, Alkassim RS. Comparison of convenience sampling and purposive sampling. Am J Theoretical Appl Stat. 2016;5 (1):1-4. doi:10.11648/j.ajtas.20160501.11

36. Cohen D, Crabtree B. Using Qualitative Methods in Healthcare Research: A Comprehensive Guide for Designing, Writing, Reviewing and Reporting Qualitative Research. Princeton, NJ: Robert Wood Johnson Foundation; 2006.

37. World Health Organization. Violence Against Women: What Health Workers Can Do. Vol. 18; 1997:2008

38. Creswell JW, Creswell JD. Research Design: Qualitative, Quantitative, and Mixed Methods Approaches. Sage publications; 2017.

39. Allison Tong PS, Craig J. Consolidated criteria for reporting qualitative research (COREQ): a 32-item checklist for interviews and focus groups. Int J Qual Health Care. 2007;19(6):349-357. doi:10.1093/ intqhe/mzm042 
40. Baird K. Women's lived experiences of domestic violence during pregnancy (1). Pract Midwife. 2015;18(3):27-31.

41. Bianchi AL, McFarlane J, Cesario S, Symes L, Maddoux J. Continued intimate partner violence during pregnancy and after birth and its effect on child functioning. J Obst Gynecol Neonatal Nurs. 2016;45(4):601-609. doi:10.1016/j.jogn.2016.02.013

42. Cizmeli C, Lobel M, Harland KK, Saftlas A. Stability and change in types of intimate partner violence across pre-pregnancy, pregnancy, and the postpartum period. Women's Reprod Health. 2018;5 (3):153-169. doi:10.1080/23293691.2018.1490084

43. Martin SL, Mackie L, Kupper LL, et al. Physical abuse of women before, during, and after pregnancy. JAMA. 2001;285 (12):1581-1650. doi:10.1001/jama.285.12.1581

44. O'Leary KD. Psychological abuse: a variable deserving critical attention in domestic violence. Violence Vict. 1999;14:3-24. doi:10.1891/ 0886-6708.14.1.3

45. Follingstad DR, Rutledge LL, Berg BJ, Hause ES, Polek DS. The role of emotional abuse in physically abusive relationships. $J$ Fam Violence. 1990;5(2):107-120. doi:10.1007/BF00978514

46. Sackett LA, Saunders DG. The impact of different forms of psychological abuse on battered women. Violence Vict. 1999;14(1):105-117. doi:10.1891/0886-6708.14.1.105

47. Mojahed A, Alaidarous N, Kopp M, Pogarell A, Thiel F, GarthusNiegel S. Prevalence of intimate partner violence among intimate partners during the perinatal period: a narrative literature review. Front Psychiatry. 2021;12:61. doi:10.3389/fpsyt.2021.601236

48. Das S, Bapat U, More NS, et al. Intimate partner violence against women during and after pregnancy: a cross-sectional study in Mumbai slums. BMC Public Health. 2013;13(1):817.

49. Nasrullah M, Zakar R, Zakar MZ, Abbas S, Safdar R. Circumstances leading to intimate partner violence against women married as children: a qualitative study in Urban Slums of Lahore, Pakistan. BMC Int Health Hum Rights. 2015;15(1):23. doi:10.1186/s12914-015-0060-0

50. Hellmuth JC, Gordon KC, Stuart GL, Moore TM. Risk factors for intimate partner violence during pregnancy and postpartum. Arch Women's Mental Health. 2013;16(1):19-27. doi:10.1007/s00737012-0309-8

51. Hellmuth J, Gordon K, Stuart G, Moore T. Women's intimate partner violence perpetration during pregnancy and postpartum. Matern Child Health J. 2013;17(8):1405-1413. doi:10.1007/s10995-012-1141-5

52. Burch RL, Gallup GG Jr. Perceptions of paternal resemblance predict family violence. Evol Hum Behav. 2000;21(6):429-435. doi:10.1016/ S1090-5138(00)00056-8
53. McLain DK, Setters D, Moulton MP, Pratt AE. Ascription of resemblance of newborns by parents and nonrelatives. Evol Hum Behav. 2000;21(1):11-23. doi:10.1016/S1090-5138(99)00029-X

54. Faramarzi M, Esmaelzadeh S, Mosavi S. Prevalence, maternal complications and birth outcome of physical, sexual and emotional domestic violence during pregnancy. Acta Med Iran. 2005;43:115-122.

55. Berhanie E, Gebregziabher D, Berihu H, Gerezgiher A, Kidane G. Intimate partner violence during pregnancy and adverse birth outcomes: a case-control study. Reprod Health. 2019;16(1):22. doi:10.1186/s12978-019-0670-4

56. Covington DL, Hage M, Hall T, Mathis M. Preterm delivery and the severity of violence during pregnancy. J Reprod Med. 2001;46 (12):1031-1039.

57. Antai D. Controlling behavior, power relations within intimate relationships and intimate partner physical and sexual violence against women in Nigeria. BMC Public Health. 2011;11(1):511. doi:10.1186/ 1471-2458-11-511

58. Mulatu S. Domestic Violence Against Women: The Case Study of Kolfe Keranyo Sub-City. Addis Ababa University; 2007.

59. Priya N, Abhishek G, Ravi V, et al. Study on Masculinity, Intimate Partner Violence and Son Preference in India. New Delhi: International Center for Research on Women; 2014.

60. Miller E, Decker MR, McCauley HL, et al. A family planning clinic partner violence intervention to reduce risk associated with reproductive coercion. Contraception. 2011;83(3):274-280. doi:10.1016/j. contraception.2010.07.013

61. Munro-Kramer ML, Scott N, Boyd CJ, et al. Postpartum physical intimate partner violence among women in rural Zambia. Int J Gynecol Obstet. 2018;143(2):199-204. doi:10.1002/ijgo.12654

62. Tabb KM, Huang H, Valdovinos M, et al. Intimate partner violence is associated with suicidality among low-income postpartum women. $J$ Women's Health. 2018;27(2):171-178. doi:10.1089/jwh.2016.6077

63. Kita S, Chan KL, Tobe H, et al. A follow-up study on the continuity and spillover effects of intimate partner violence during pregnancy on postnatal child abuse. $J$ Interpers Violence. 2019;36:0886260518821460.

64. Parrish JW, Lanier P, Newby-Kew A, Arvidson J, Shanahan M. Maternal intimate partner violence victimization before and during pregnancy and postbirth child welfare contact: a population-based assessment. Child Maltreat. 2016;21(1):26-36. doi:10.1177/ 1077559515616704

65. World Medical Association. World Medical Association Declaration of Helsinki: ethical principles for medical research involving human subjects. JAMA. 2013;310(20):2191-2194. doi:10.1001/jama.2013.281053

\section{Publish your work in this journal}

The International Journal of Women's Health is an international, peerreviewed open-access journal publishing original research, reports, editorials, reviews and commentaries on all aspects of women's healthcare including gynecology, obstetrics, and breast cancer. The manuscript management system is completely online and includes a very quick and fair peer-review system, which is all easy to use. Visit http://www.dovepress.com/testimonials.php to read real quotes from published authors. 